\title{
Antimicrobial Activity of Nanostructured Composites Produced in Al/Zn Nanoparticle Oxidation in Aqueous-Alcoholic Solutions
}

\author{
Aleksandr S. Lozhkomoev ${ }^{1,2, a)}$, Elena A. Glazkova ${ }^{1,2, b)}$, \\ Natalia V. Svarovskaya ${ }^{1,2,3, \text { c) }}$, Olga V. Bakina ${ }^{1,2, \text { d) }}$, Elena G. Khorobraya ${ }^{1, \text { e) }}$, \\ Sergey S. Timofeev ${ }^{1, \text { f) }}$, Vladimir V. Domashenko ${ }^{1, \text { g) }}$, and Sergey G. Psakhie ${ }^{1,2, \text { h) }}$ \\ ${ }^{I}$ Institute of Strength Physics and Materials Science SB RAS, Tomsk, 634055, Russia \\ ${ }^{2}$ National Research Tomsk Polytechnic University, Tomsk, 634050, Russia \\ ${ }^{3}$ National Research Tomsk State University, Tomsk, 634050, Russia

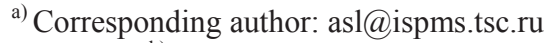 \\ b)eagl@ispms.tsc.ru \\ c)nvsv@ispms.tsc.ru \\ d) ovbakina@ispms.tsc.ru \\ e)egx@mail.ru \\ f) timofeev-ss@mail.ru \\ g)vvdom1984@gmail.com \\ h) sp@ms.tsc.ru
}

\begin{abstract}
The paper studies the morphology, phase and elemental composition of bimetallic Al/Zn nanoparticles. It is found that metallic $\mathrm{Al}$ and $\mathrm{Zn}$ phases have interfaces within a single particle. The conversion mechanisms of $\mathrm{Al} / \mathrm{Zn}$ nanoparticles in aqueous-alcoholic solutions with different water concentration are studied. It is shown that at 7 mass\% water content aluminum oxidation and pseudoboehmite formation begin. Aluminum conversion increases with water content growth. At 20 mass\% water content aluminum is oxidized completely, giving way to zinc oxidation. Microbiological studies show that samples containing AlOOH-Zn-ZnO phases exhibit the highest antimicrobial activity. Two-component metallic $\mathrm{Al} / \mathrm{Zn}$ nanoparticles and composite particles in which initial components are completely oxidized to $\mathrm{AlOOH}-\mathrm{ZnO}$ have the smallest inhibition zone.
\end{abstract}

Keywords: bimetallic nanoparticles, oxidation, nanostructured composites, antimicrobial activity

\section{INTRODUCTION}

In recent years, the appearance of resistant microbial strains has raised the importance of developing new antimicrobial materials that can provide an alternative to conventional antibiotic and antiseptic drugs [1]. An upcoming trend is to use metal and metal compound nanoparticles as antibacterials [2, 3]. The application of nanoparticles with large specific surface allows a significant reduction of metal concentration (and, consequently, drug toxicity) without deterioration of antimicrobial activity [4]. Low-cost zinc and its compounds are an attractive antibacterial for medical products and disposable medical wear [5]. Materials that contain an adsorbent or an antimicrobial represented by one particle offer good opportunities for biomedicine [6]. These materials include composite particles containing low-dimensional pseudoboehmite structures and nanosized zinc particles synthesized by hydrolysis of electroexplosive $\mathrm{Al} / \mathrm{Zn}$ nanopowder. Composite particles exhibiting high antimicrobial activity are promising materials for the production of medical products. The aim of the present paper is to study the conversion

International Conference on Physical Mesomechanics of Multilevel Systems 2014

AIP Conf. Proc. 1623, 367-370 (2014); doi: 10.1063/1.4898958

(C) 2014 AIP Publishing LLC 978-0-7354-1260-6/ $\$ 30.00$ 
mechanisms, physical and chemical as well as antimicrobial properties of composite particles depending on the depth at which $\mathrm{Al} / \mathrm{Zn}$ reacts with water.

\section{EXPERIMENTAL PROCEDURE}

A precursor for composite particle synthesis was bimetallic Al/Zn particles. The particles were synthesized by electrical explosion of two twisted aluminum and zinc wires in argon atmosphere at equal mass content of metals [7]. In order to understand the mechanisms of the formation of low-dimensional structures and synthesis of composite particles of different morphology, oxidation of $\mathrm{Al} / \mathrm{Zn}$ nanoparticles was carried out in aqueous-alcoholic solutions with different water/alcohol ratio. The content of powder in the solution in all cases was $25 \mathrm{~g} / 1$, the reaction temperature was $60^{\circ} \mathrm{C}$, and the reaction time was $60 \mathrm{~min}$.

The morphology of samples was examined by transmission electron microscopy (JEM 2100, JEOL, Japan). The elemental composition and spatial element distribution in the scan area were analyzed by elemental mapping on a microscope equipped with an X-Max SDD detector. The phase composition was defined by X-ray diffraction with $\mathrm{CuK}_{\alpha}$ radiation, $\lambda=1.54056 \AA$ (diffractometer XRD-6000, Shimadzu). The specific surface area was evaluated by thermal desorption of nitrogen (Sorbometr M, Katakon, Russia) and calculated by the five-point BET method. The zinc ion concentration in water was determined by stripping voltammetry (system STA, LLC "UMH", Russia). The antimicrobial activity of samples was estimated by radial diffusion in agar using bacteria Escherichia Coli K-12 CL588 [8].

\section{RESULTS AND DISCUSSION}

$\mathrm{Al} / \mathrm{Zn}$ nanoparticles (sample I) are mostly spherical in shape, which is typical for electroexplosive powders. $\mathrm{Al} / \mathrm{Zn}$ nanopowder consists of $\mathrm{Zn}$ and $\mathrm{Al}$ phases. According to energy dispersive analysis (Fig. 1(a)) showing the distribution of chemical elements in particles, there are well-defined regions of zinc or aluminum. The metallic phases are divided by an interface within a single particle, which agrees with the state diagram of $\mathrm{Al}$ and $\mathrm{Zn}$ metals immiscible in the solid state. The mean particle size distribution for $\mathrm{Al} / \mathrm{Zn}$ nanoparticles is $98 \mathrm{~nm}$. The specific surface area of the powder is $5 \mathrm{~m}^{2} / \mathrm{g}$ (Table 1 ).

During $\mathrm{Al} / \mathrm{Zn}$ nanoparticle oxidation by water in an aqueous-alcoholic reaction medium, ethyl alcohol acts as an antioxidant inhibiting the access of water to the surface of reacting nanoparticles. At a less than 7 mass $\%$ water content in the reaction medium, no signs of reaction ( $\mathrm{pH}$ variation, gas release) were observed even at a quantity of water (reagent) stoichiometrically required for the reaction to start. The microstructure of particles and their specific surface area were the same as in the initial powder (sample I). Conversion of nanoparticles begins at 7 mass $\%$ water content (sample II, Fig. 1(b)). Analysis of the morphology of sample II has shown that a few low-dimensional structures in the form of folded nanosheets are formed around reacting particles. The main phases are $\mathrm{Al}, \mathrm{Zn}$ and pseudoboehmite AlOOH formed in aluminum oxidation by water [9]. The specific surface area of sample II is $8 \mathrm{~m}^{2} / \mathrm{g}$ (Table 1). Owing to higher chemical activity of Al, it first reacts with water to form low-dimensional pseudoboehmite structures.

TABLE 1. Physical, chemical and antimicrobial properties of nanostructured composites

\begin{tabular}{cccccc}
\hline Sample & $\begin{array}{c}\text { Water Content in the } \\
\text { Reaction Mixture, mass } \%\end{array}$ & Phase Composition & $\boldsymbol{S}_{\text {sp }}, \mathbf{~ m}^{\mathbf{2}} \mathbf{g}$ & $\begin{array}{c}\mathbf{Z n}^{2+} \text { Concentra- } \\
\text { tion, } \mathbf{m g} / \mathbf{l}\end{array}$ & ZOI, mm \\
\hline I & precursor & $\mathrm{Al}, \mathrm{Zn}$ & 5 & 0.231 & $8.1 \pm 0.1$ \\
\hline II & 7 & $\mathrm{Al}, \mathrm{Zn}, \mathrm{AlOOH}$ & 8 & 0.227 & $9.1 \pm 0.4$ \\
\hline III & 15 & $\mathrm{Al}, \mathrm{Zn}, \mathrm{AlOOH}$ & 18 & 0.242 & $9.3 \pm 0.3$ \\
\hline IV & 20 & $\mathrm{Al}, \mathrm{Zn}, \mathrm{AlOOH}, \mathrm{ZnO}$ & 56 & 0.347 & $13.4 \pm 0.6$ \\
\hline V & 35 & $\mathrm{Al}, \mathrm{Zn}, \mathrm{AlOOH}, \mathrm{ZnO}$ & 86 & 0.117 & $8.4 \pm 0.5$ \\
\hline VI & 100 & $\mathrm{Al}, \mathrm{Zn}, \mathrm{AlOOH}, \mathrm{ZnO}$ & 100 & 0.153 & $8.4 \pm 0.2$ \\
\hline
\end{tabular}



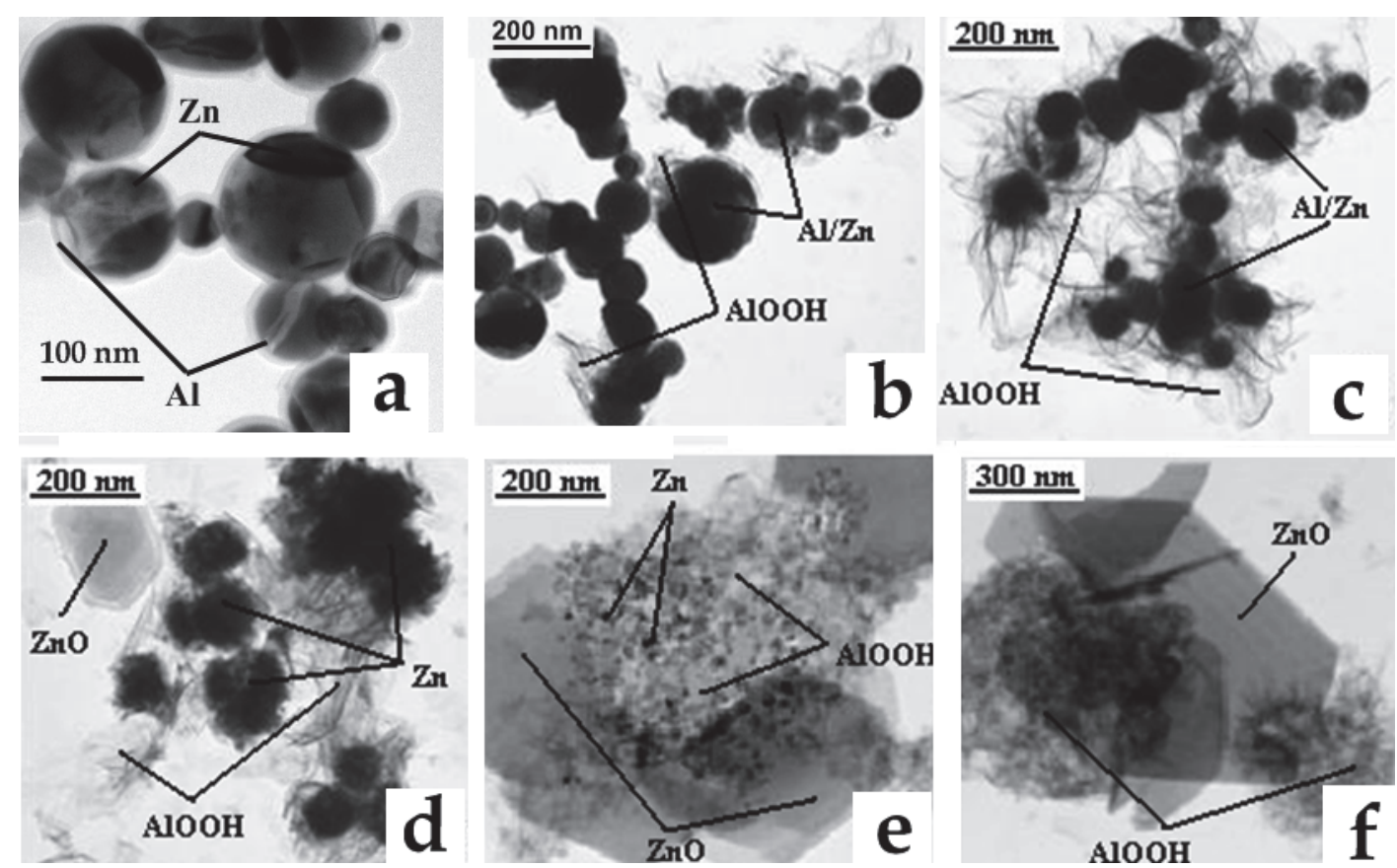

FIGURE 1. TEM images of Al/Zn nanoparticles and their oxidation products in aqueous-alcoholic solutions with different water content, mass\%: sample I, Al/Zn nanoparticles (a); sample II, 7\% (b); sample III, 15\% (c); sample IV, 20\% (d); sample V, 35\% (e), sample VI, $100 \%$ (f)

An increase in water content up to 15 mass\% (sample III) causes an increase in aluminum conversion, the number of pseudoboehmite nanosheets around the initial powder nanoparticles increases (Fig. 1(c)), and the specific surface area grows up to $18 \mathrm{~m}^{2} / \mathrm{g}$. At further water content growth up to 20 mass\% (sample IV, Fig. 1(d)), the specific surface area of conversion products increases $\left(56 \mathrm{~m}^{2} / \mathrm{g}\right)$, which is indicative of increasing reaction depth. Aluminum is almost completely converted and forms agglomerates of low-dimensional structures; in so doing the microstructure of reacting nanoparticles changes. The electron-dense areas within the agglomerates are probably made up by inclusions of metallic zinc phase (Fig. 1(d)). According to X-ray diffraction phase analysis, ZnO phase forms in sample IV.

Sample V separated from the reaction medium with 35 mass\% water content is represented by two types of lowdimensional structures: $\mathrm{AlOOH}$ nanosheets, and $\mathrm{ZnO}$ hexagonal plates (Fig. 1(e)). Besides, analysis reveals a small amount of metallic aluminum and zinc in sample V. The specific surface area of the sample reaches $86 \mathrm{~m}^{2} / \mathrm{g}$. Sample VI is obtained in water (Fig. 1(f)); it is mainly composed of $\mathrm{AlOOH}$ and $\mathrm{ZnO}$ phases, which is testimony to almost complete conversion of $\mathrm{Al} / \mathrm{Zn}$ nanoparticles. The specific surface area increases significantly depending on the depth of nanoparticle oxidation and attains $100 \mathrm{~m}^{2} / \mathrm{g}$. The increase in the specific surface area is to a large extent related to the formation of low-dimensional $\mathrm{AlOOH}$ structures that exhibit a high capacity of adsorbing microorganisms and their metabolic and decomposition products [10].

The study of the antimicrobial activity of the synthesized nanostructured composites (Table 1) has shown that all samples have antibacterial properties. Samples I, V and VI exhibited the lowest antimicrobial activity towards E.Coli; the inhibition zone (ZOI) was $8.1 \pm 0.1,8.4 \pm 0.5$ and $8.4 \pm 0.2$, respectively. Sample IV had the highest antimicrobial activity (Fig. 1(d)); ZOI was $13.4 \pm 0.6 \mathrm{~mm}$ after 48 hours of exposure. Analysis of aqueous extracts from the nanostructured composite samples has shown that the aqueous extract from sample IV has a low concentration of $\mathrm{Zn}^{2+}$ ions. This is evidently due to the fact that during conversion of $\mathrm{Al} / \mathrm{Zn}$ nanoparticles, aluminum oxidation and formation of low-dimensional $\mathrm{AlOOH}$ structures the microstructure is disturbed and reacting particles are fragmented. The reactive surface area of metallic zinc therewith increases; zinc is dissolved with the formation of $\mathrm{Zn}^{2+}$ ions that exert the greatest antimicrobial effect. The amount of $\mathrm{Zn}^{2+}$ ions reduces with zinc oxidation and the antimicrobial effect decreases. 


\section{CONCLUSION}

Nanostructured composites of complex morphology are synthesized by oxidation of electroexplosive $\mathrm{Al} / \mathrm{Zn}$ particles in aqueous-alcohol solutions. Electron microscopy and X-ray diffraction phase analysis are used to examine initial $\mathrm{Al} / \mathrm{Zn}$ particles and their oxidation products depending on the content of water in the solution. It is shown that the growing water content in the reaction medium causes an increase in nanoparticle conversion and an increase in the specific surface area of samples owing to the formation of low-dimensional AlOOH structures and hexagonal $\mathrm{ZnO}$ plates. The samples containing $\mathrm{AlOOH}-\mathrm{Zn}-\mathrm{ZnO}$ phases, from which $\mathrm{Zn}^{2+}$ ions are released to the nutrient solution, exhibit the highest antimicrobial activity.

\section{ACKNOWLEDGEMENTS}

Bimetallic Al/Zn nanoparticles are synthesized during research supported by RFBR Grant 14-08-31363. Synthesis of nanostructured composites and study of their antimicrobial activity are carried out in the framework of the Program of Fundamental Researches of the State Academies of Sciences for 2013-2020. The authors are thankful to the Nanotech Sharing Center of ISPMS SB RAS for TEM and XRD analyses.

\section{REFERENCES}

1. Antimicrobial Resistance: Global Report on Surveillance, World Health Organization, Geneva, 2014, see http://apps.who.int/iris/bitstream/10665/112642/1/9789241564748_eng.pdf?ua=1, accessed 2 June 2014.

2. M. Rai, A. Yadav, and A. Gade, Biotechnol. Adv. 27, 76 (2009).

3. A. Azam, A. S. Ahmed, M. Oves, M. S. Khan, and A. Memic, Int. J. Nanomed. 7, 3527 (2012).

4. J. P. Ruparelia, A. K. Chatterjee, S. P. Duttagupta, and S. Mukherji, Acta Biomater. 4, 707 (2008).

5. M. F. Khan, M. Hameedullah, A. H. Ansari, E. Ahmad, M. B. Lohani, R. H. Khan, M. M. Alam, W. Khan, F. M. Husain, and I. Ahmad, Int. J. Nanomed. 9, 853 (2013).

6. V. Stanic, S. Dimitrijevic, J. Antic-Stankovic, M. Mitric, B. Jokic, I. B. Plecas, and S. Raicevic, Appl. Surf. Sci. 256, 6083 (2010).

7. M. I. Lerner, E. A. Glazkova, V. V Domashenko, S. S. Timofeev, and A. V. Pervikov, Izv. Vuzov. Fizika 55, 209 (2012).

8. C. Perez, M. Paul, and P. Bazerque, Acta. Biol. Med. Exp. 15, 113 (1990).

9. N. V. Svarovskaya, O. V. Bakina, E. A. Glazkova, M. I. Lerner, and S. G. Psakhie, Russ. J. Phys. Chem. A 84, $1566(2010)$.

10. M. I. Lerner, O. V. Bakina, E. A. Glazkova, A. S. Lozhkomoev, N. V. Svarovskaya, and S. G. Psahie, Inorg. Mat. 2, 488 (2011). 